\title{
Effects of targeted Notch1 silencing on the biological processes of the T24 and 5637 cells in vitro
}

\author{
KEWEN ZHENG $^{1 *}$, XIAOMIN HAN ${ }^{2 *}$, YAN SU$^{2}$, QINGHAI WANG ${ }^{3}$, QIANG MA ${ }^{2}$ and $\mathrm{KESI} \mathrm{ZHENG}^{4}$
}

\author{
${ }^{1}$ Department of Urology, The First Affiliated Hospital of Wenzhou Medical University, \\ The First Clinical College of Wenzhou Medical University, Wenzhou, Zhejiang 325000; ${ }^{2}$ Blood Conservation Institute, \\ School of Basic and Forensic Medicine, Baotou Medical College, Baotou, Inner Mongolia Autonomous Region 014040; \\ ${ }^{3}$ Department of Kidney Transplantation, The Affiliated Hospital of Qingdao University, Qingdao, Shandong 266003; \\ ${ }^{4}$ Department of Thyroid and Breast Surgery, Wenzhou People's Hospital, \\ The Third Clinical College of Wenzhou Medical University, Wenzhou, Zhejiang 325000, P.R. China
}

Received January 20, 2020; Accepted November 26, 2020

DOI: $10.3892 / 01.2021 .12566$

\begin{abstract}
The present study aimed to investigate the roles of Notchl in the biological processes of bladder cancer cells (BCCs) in vitro. Short hairpin (sh)RNA targeting Notch1 was designed and constructed, and the T24 and 5637 BCCs were selected for transfection. The cells were classified into two groups: shRNA negative control (NC) and Notch1 shRNA. MTT and Transwell assays, and flow cytometry were performed to examine the changes in cell proliferation, invasiveness, and apoptosis, respectively. In addition, reverse transcription-quantitative PCR and western blot analysis was used to detect the mRNA and protein expression levels of apoptosis-related proteins ( $\mathrm{Bax}$, Bid and $\mathrm{Bcl} 2$ ) and epithelial-mesenchymal transition factors (vimentin and E- and $\mathrm{N}$-cadherin). Compared with that in the shRNA NC group, the Notch1 shRNA group showed significantly decreased cell proliferation rate and invasiveness; increased apoptotic rate; elevated mRNA expression levels of Bad, Bid and E-cadherin; and reduced mRNA expression levels of $\mathrm{Bcl} 2, \mathrm{~N}$-cadherin and vimentin. The trends for protein expression levels were the same as those for mRNA levels. Notchl silencing inhibited invasion and promoted apoptosis of BCCs.
\end{abstract}

Correspondence to: Dr Kesi Zheng, Department of Thyroid and Breast Surgery, Wenzhou People's Hospital, The Third Clinical College of Wenzhou Medical University, 299 Gu'an Road, Wenzhou, Zhejiang 325000, P.R. China

E-mail: fvwrj3@163.com

Dr Qiang Ma, Blood Conservation Institute, School of Basic and Forensic Medicine, Baotou Medical College, 31 Jianshe Road, Baotou, Inner Mongolia Autonomous Region 014040, P.R. China E-mail: 102016027@btmc.edu.cn

*Contributed equally

Key words: Notch1, bladder cancer cells, apoptosis, invasion, epithelial-mesenchymal transition

\section{Introduction}

Bladder cancer is a prevalent urinary system malignancy, that seriously threatens human health and life. According to the study $\sim 430,000$ new cases of bladder cancer were reported worldwide in 2012, of which 165,000 were fatal (1). Bladder cancer is divided into non-muscle-invasive bladder cancer (NMIBC) and muscle-invasive bladder cancer (MIBC) (2). In total, $\sim 75 \%$ of patients with bladder cancer are diagnosed with NMIBC (3). Transurethral resection of bladder tumors is the major form of treatment for NMIBC. Regular intravesical chemotherapy is administered following surgery to prevent recurrence (4). However, $\sim 50-70 \%$ of patients with NMIBC suffer from disease recurrences, and $30-40 \%$ of these patients suffer from disease progression $(3,5,6)$. Data obtained from studies published between 2006 and 2011 showed the 4-year survival rate of patients with MIBC after progression from high-risk NMIBC was $35 \%$ (7). Pelvic lymph node dissection is not only a treatment method, but also provides important information on prognosis. Studies have shown that the risk of lymphatic metastasis in muscular invasive bladder cancer was over $24 \%$ and was associated with the depth of tumor invasion (pT2a 9-18\%, pT2b 22-41\%, pT3 41-50\%, pT4 41-63\%). Therefore, pelvic lymph node dissection is an important part of radical cystectomy. Due to the high incidence and recurrence rates, it is necessary to investigate the relevant genetic pathways underlying the genesis and development of bladder cancer.

Notchl is involved in the proliferation and differentiation of various cells, such as human dental pulp stem cells $(8,9)$ and neural stem cells (8). Studies have demonstrated that Notch1 expression in bladder cancer cells (BCCs) was associated with their malignancy $(10,11)$. Notchl silencing, using shRNA, could inhibit the proliferation of 5637 BCCs (12). However, the specific mechanism of action of Notchl in BCCs remains unclear.

Therefore, in the present study, Notchl was silenced in human T24 and 5637 BCCs to observe its effects on the invasion potential, apoptosis, and epithelial-mesenchymal transition (EMT) of these cells. 


\section{Materials and methods}

Experimental materials. Human T24 and 5637 BCCs were purchased from Procell Life Science \& Technology Co., Ltd. The BCA protein assay kit was purchased from Beyotime Institute of Biotechnology, while the PLVX-shRNA2 vector was purchased from Addgene, Inc. TRIzol ${ }^{\circledR}$ reagent and restriction endonucleases (ExoRI and BamHI) were purchased from Thermo Fisher Scientific, Inc. Reverse transcription (RT) and SYBR-Green PCR kits were purchased from Takara Biotechnology, Co., Ltd. Rabbit monoclonal antibodies against $\mathrm{E}$-cadherin, $\mathrm{N}$-cadherin, vimentin, and Bcl2 were purchased from Cell Signaling Technology, Inc. Rabbit polyclonal antibodies against Bad and Bid were purchased from ProteinTech Group, Inc. and Abcam, respectively. The Transwell chambers were purchased from BD Biosciences, while the apoptosis detection and cell cycle detection kits were purchased from Nanjing KeyGen Biotech Co., Ltd.

Cell culture. The T24 and 5637 cell lines were removed from liquid nitrogen and thawed in a water bath at $37^{\circ} \mathrm{C}$ for up to $1 \mathrm{~min}$. The cells were cultured in RPMI-1640 medium (Gibco; Thermo Fisher Scientific, Inc.) supplemented with penicillin $(100 \mathrm{U} / \mathrm{ml})$, streptomycin $(0.1 \mathrm{mg} / \mathrm{l})$ and $10 \% \mathrm{FBS}$, and maintained at $37^{\circ} \mathrm{C}$ in a humidified incubator with $5 \% \mathrm{CO}_{2}$. The cells were passaged when they reached $\sim 80 \%$ confluence.

Plasmid construction and transfection. The Notch1 scrambled negative control short hairpin (sh) RNA (shRNA NC) and Notch1 interference (Notch1 shRNA) sequences used were biosynthesized by Shanghai GenePharma Co., Ltd., and designed according to GeneID, 4851 (Table I). After annealing to form double strands, the shRNA NC or Notch1 shRNA sequences were cloned into the PLVX-shRNA2 vector pre-digested with ExoRI and BamHI. After being transfected into competent Escherichia coli DH5a cells, the plasmids were extracted from one single colony and Sanger sequencing was performed to verify the presence of the cloned plasmids. For shRNA $(2 \mu \mathrm{g})$ and PLVX vector transfection, the T24 and 5637 cell lines during the logarithmic growth stage were seeded into 24 -well plates to adjust the cell density to $4 \times 10^{5} /$ well, which corresponded to $70-80 \%$ confluency. In accordance with the manufacturer's instructions, Lipofectamine ${ }^{\circledR} 2000$ transfection (Invitrogen; Thermo Fisher Scientific, Inc.) reagent was used to transfect the plasmids into the T24 and 5637 cell lines. After $8 \mathrm{~h}$ of transfection, at $37^{\circ} \mathrm{C}$ with $5 \% \mathrm{CO}_{2}$, the RPMI 1640 -medium containing $1 \%$ ampicillin, used upon transfection $(30 \mu \mathrm{g} / \mathrm{ml})$ was replaced with normal medium. The cells were cultured in a constant-temperature incubator at $37^{\circ} \mathrm{C}$ with $5 \% \mathrm{CO}_{2}$. After $48 \mathrm{~h}$, the cells were collected for subsequent experiments. Notch1 mRNA expression levels in the T24 and 5637 transfected cells were detected using RT-quantitative PCR.

MTT assay. The cells in the logarithmic growth phase were cultured overnight in an incubator at $37^{\circ} \mathrm{C}$ with $5 \% \mathrm{CO}_{2}$. Then, $100 \mu \mathrm{l} /$ well cell suspension $\left(5 \times 10^{4}\right.$ cells $\left./ \mathrm{ml}\right)$ were seeded in a 96-well plate and cultured at $37^{\circ} \mathrm{C}$ with $5 \% \mathrm{CO}_{2}$ for $4 \mathrm{~h}$. After incubation with MTT (Nanjing SenBeiJia Biological Technology Co., Ltd.), $0.15 \mathrm{ml}$ DMSO (Beijing Solarbio Science and Technology Co., Ltd.) was added and the suspension was shaken for $10 \mathrm{~min}$. Optical density (OD) at $568 \mathrm{~nm}$ was measured using a microplate reader. The experiments were performed independently 3 times.

Transwell assay. After $48 \mathrm{~h}$ of successful transfection, the cells in each group were digested with $0.25 \%$ trypsin, collected and centrifuged at $300 \mathrm{xg}$, at $4^{\circ} \mathrm{C}$. The cells were then washed twice with pre-cooled PBS. Cells were suspended in a serum-free RPMI-1640 medium and counted using the plate count method, by visually observing the number of cells. Next, $0.8 \mathrm{ml}$ medium with $10 \%$ FBS was transferred into a 24-well plate, which was then placed in a Transwell chamber. Then, $1 \mathrm{mg} / \mathrm{ml}$ Matrigel $(100 \mu \mathrm{l})$ was added vertically to the bottom of the upper Transwell chamber. After the Matrigel solidified, $200 \mu \mathrm{l}$ cell suspension $\left(1 \times 10^{7}\right)$ was added to the upper Transwell chamber and cultured at $37^{\circ} \mathrm{C}$ in a humidified incubator with $5 \% \mathrm{CO}_{2}$ for $24 \mathrm{~h}$. The Transwell was then removed, the chamber was washed with PBS and the cells were fixed in $10 \%$ methanol for $30 \mathrm{~min}$ at $4^{\circ} \mathrm{C}$. Then, the membrane was removed and the cells were stained with crystal violet $(0.5 \%)$ at room temperature for 20 min, followed by a wash with PBS. Images were acquired and the cell numbers calculated using a counting slide, under a light microscope (magnification, x20; Olympus Corporation). The experiments were performed independently 3 times.

Flow cytometry for apoptosis. After 2 days in culture, the cells were subjected to trypsin digestion $(0.25 \%)$ and then collected in a flow cytometry tube. A total of $\sim 1 \times 10^{5}$ suspended cells were centrifuged at $300 \mathrm{x} \mathrm{g}$, at $4^{\circ} \mathrm{C}$. Detection was conducted following the instructions of the Annexin V-APC/7-AAD detection kit. The cells were resuspended in binding buffer $\left(0.05 \mathrm{ml} ; 5 \times 10^{5} / \mathrm{ml}\right)$, followed by the addition of the 7-AAD solution $(5 \mu \mathrm{l})$, and incubated for $15 \mathrm{~min}$ at room temperature. Finally, $0.45 \mathrm{ml}$ binding buffer and $1 \mu 1$ Annexin V-APC were added at room temperature in the dark for $15 \mathrm{~min}$. The cell cycle distribution was evaluated using a FACSVerse ${ }^{\mathrm{TM}}$ flow cytometer (Beckman Coulter, Inc.) and the data were analyzed using FlowJo v10 software (FlowJo LLC). The experiments were performed independently 3 times.

Cell cycle analysis. The cells were cultured for $48 \mathrm{~h}$ following transfection, then digested with $0.25 \%$ non-EDTA trypsin, followed by centrifugation at $300 \mathrm{xg}$, at room temperature for 5 min to harvest the cells. The cells were then resuspended in $100 \mathrm{ml}$ PBS, and fixed by slowly adding $700 \mathrm{ml}$ pre-cooled $80 \%$ ethanol to reach a final concentration of $70 \%$, following incubation at $4^{\circ} \mathrm{C}$ for $4 \mathrm{~h}$ before centrifugation at $300 \mathrm{x} \mathrm{g}$ for $5 \mathrm{~min}$, at $4^{\circ} \mathrm{C}$. Then, RNase $(100 \mathrm{ml} ; 50 \mu \mathrm{g} / \mathrm{ml})$ was added, and the cells were placed in a water bath at $37^{\circ} \mathrm{C}$ for $30 \mathrm{~min}$ to permeabilize the cells. Finally, PI solution $(400 \mu \mathrm{l} ; 50 \mu \mathrm{g} / \mathrm{ml})$ was added, and the cells were stained at $4^{\circ} \mathrm{C}$ for $30 \mathrm{~min}$ in the dark. The cell cycle distribution was evaluated using FACSVerse $^{\mathrm{TM}}$ flow cytometer (Beckman Coulter, Inc.) and the data were analyzed using FlowJo v10 software (FlowJo LLC). The experiments were performed independently 3 times.

$R T-q P C R$. After the T24 and 5637 cells were transfected and cultured for $48 \mathrm{~h}$, total RNA was isolated using TRIzol ${ }^{\circledR}$ following the manufacturer's instructions. RT was performed to synthetize cDNA using a Prime Script RT kit (Takara,cat.no.RR037A; Takara Bio, Inc.) at $65^{\circ} \mathrm{C}$ for $10 \mathrm{~min}$ [RNA, oligo(dT), random primer and 
Table I. shRNA sequence list.

\begin{tabular}{lll}
\hline Name & Orientation & Sequence $\left(5^{\prime}-3^{\prime}\right)$ \\
\hline Notch1-shRNA & Forward & GATCCCCAACATCCAGGACAACATTTCAAGAGAAT \\
& & GTTGTCCTGGATGTTGGTTTTTCTCGAGG \\
& Reverse & AATTCCTCGAGAAAAAACCAACATCCAGGACAA \\
shRNA-NC & CATTCTCTTGAAATGTTGTCCTGGATGTTGGG \\
& Forward & GATCCTTCTCCGAACGTGTCACGTTTCAAGAGAACGT \\
& Reverse & AATTCACGTCGGAGAATTTTTCTCGAGG \\
& & CACGTTCTCTTGAAACGTGACACGTCGGAGAAG \\
\hline
\end{tabular}

shRNA, short hairpin RNA; NC, negative control.

Table II. Primer sequences for E-cadherin, N-cadherin, vimentin, Bcl-2, Bad, Bid and GAPDH.

\begin{tabular}{lll}
\hline Name & Primer & \multicolumn{1}{c}{ Sequence } \\
\hline E-cadherin & Forward & Size, bp \\
& Reverse & 5'-CGTAGCAGTGACGAATGTGG-3' \\
N-cadherin & Forward & 5'-CTGGGCAGTGTAGGATGTGA-3' \\
& Reverse & 5'-CTTGCCAGAAAACTCCAGGG-3' \\
Vimentin & Forward & 5'-TGTGCCCTCAAATGAAACCG-3' \\
& Reverse & 5'-CGCCAACTACATCGACAAGG-3' \\
Bcl-2 & Forward & 5'-GGCTTTGTCGTTGGTTAGCT-3' \\
& Reverse & 5'-GCCTTCTTTGAGTTCGGTGG-3' \\
Bad & Forward & 5'-GAAATCAAACAGAGGCCGCA-3' \\
& Reverse & 5'-GGGACGGAGGACGACG-3' \\
Bid & Forward & 5'-CACTGGGAGGGGGCGG-3' \\
& Reverse & 5'-GGGAAGAATAGAGGCAGA-3' \\
GAPDH & Forward & 5'-GACATCACGGAGCAAGGA-3' \\
& Reverse & 5'-TCAAGAAGGTGGTGAAGCAGG-3' \\
& & 5'-TCAAAGGTGGAGGAGTGGGT-3'
\end{tabular}

water], then on ice for $5 \mathrm{~min}$. The samples were then incubated at $25^{\circ} \mathrm{C}$ for $10 \mathrm{~min}$, with the addition of dNTPs, RNaseA, buffer, MTV reverse transcriptase. Next, the samples were incubated at $37^{\circ} \mathrm{C}$ for $60 \mathrm{~min}$, then heated to $70^{\circ} \mathrm{C}$ for $10 \mathrm{~min}$. Subsequently, qPCR was subsequently performed using the SYBR-Green PCR kit, according to the manufacturer's instructions (cat. no. RR430S; Takara Bio, Inc.), to analyze the mRNA expression levels of vimentin, Bcl2, Bad, Bid, and E- and N-cadherin (primer sequences are listed in Table II). The following thermocycling conditions were used for the qPCR: Initial denaturation at $95^{\circ} \mathrm{C}$ for $30 \mathrm{sec}$, then 40 cycles of $95^{\circ} \mathrm{C}$ for $30 \mathrm{sec}$ and $60^{\circ} \mathrm{C}$ for $30 \mathrm{sec}$. The $2^{-\Delta \Delta \mathrm{Cq}}$ method was used to measure the relative mRNA expression levels (13); GAPDH was used as the internal reference gene. The experiments were performed independently 3 times.

Western blot analysis. The T24 or 5637 cells were lysed with lysis buffer (50 mM Tris-HCl, $0.5 \mathrm{mM}$ EDTA, 1\% SDS and $1 \mathrm{mM}$ DTT) on ice. The concentration of the extracted proteins from the cells were determined using a BCA assay kit (cat. no. DEM183-1000T; Beijing BioDee Biotechnology Co., Ltd.).
A total of $20 \mu \mathrm{g}$ protein was mixed with $4 \mu \mathrm{l} 2 \mathrm{X}$ SDS sample buffer. After denaturation, the samples were separated using $10 \%$ SDS-PAGE, transferred to PVDF membranes and blocked with $5 \%$ skimmed milk. Then, the membranes were incubated with the following primary antibodies: Bad (cat. no. ab32445; 1:1,000), Bid (cat. no. ab32060; 1:1,000), vimentin (cat. no. ab92547; 1:1,000), E-cadherin (cat. no. ab40772; 1:1,000), N-cadherin (cat. no. ab98952; 1:1,000), Bcl2 (cat. no. ab182858; 1:1,000) and GAPDH (cat. no. ab8245; 1:1,000) (all from Abcam) overnight at $4^{\circ} \mathrm{C}$. The membranes were then washed with PBS and horseradish peroxidase-labeled sheep anti-rabbit IgG secondary antibody $(1: 50,000)$ was added and incubated at room temperature for $60 \mathrm{~min}$. Enhanced chemiluminescence assay (cat. no. WBKLS0500; EMD Millipore) was used to detect the densitometry of the target proteins, then the OD was measured using ImageJ software (v1.8.0.112; National Institutes of Health). The experiments were performed independently 3 times.

Statistical analysis. Statistical analyses were performed using SPSS (version 22.0; IBM Corp.). Data were presented 


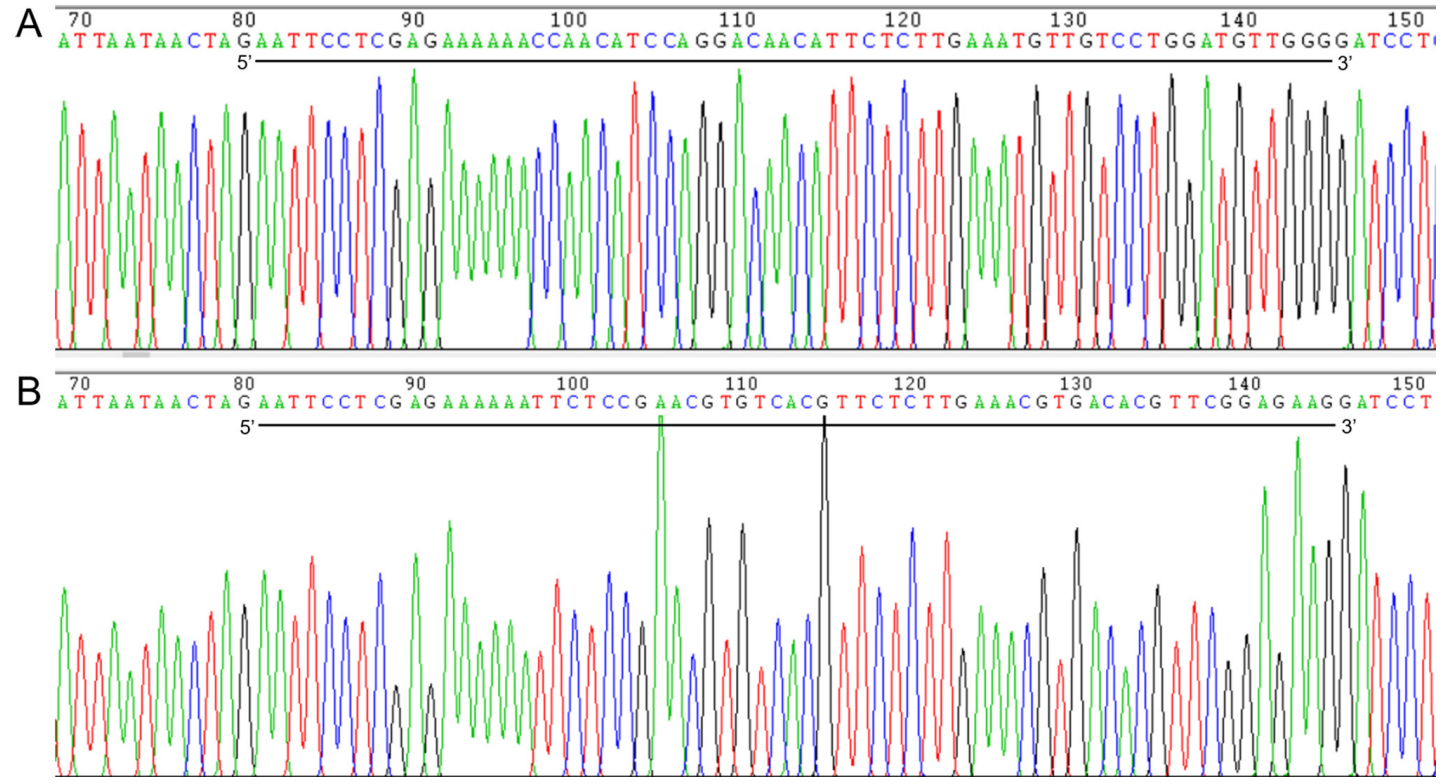

Figure 1. Sequencing and identification of Notchl (A) shRNA and (B) NC vector plasmid. The underlined bases correspond to the inserted Notchl shRNA or the NC sequence, and the non-underlined nucleotides correspond to the PLVX-shRNA2 vector backbone.

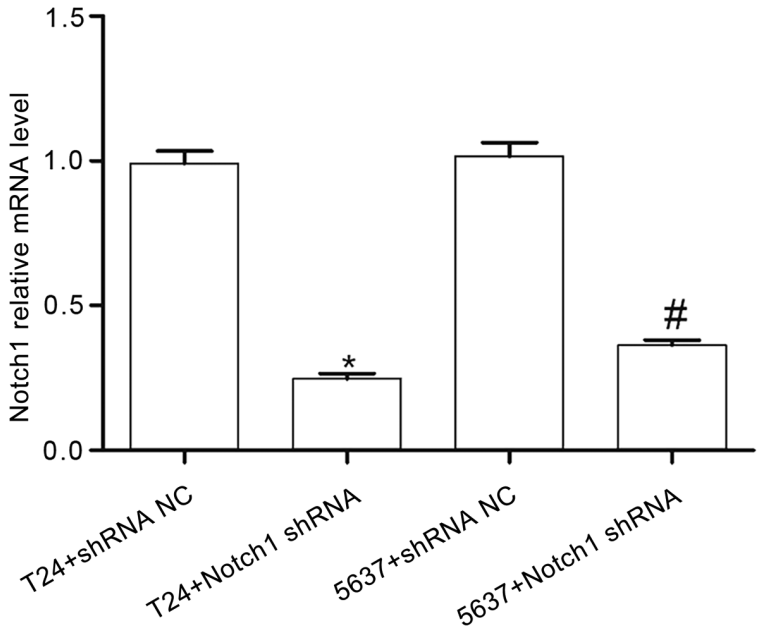

Figure 2. Changes in Notch1 mRNA expression following transfection with shRNA were detected using reverse transcription-quantitative PCR. ${ }^{*} \mathrm{P}<0.05$ vs. T24+shRNA NC; ${ }^{*} \mathrm{P}<0.05$ vs. $5637+$ shRNA NC. shRNA, short hairpin RNA; NC, negative control.

as mean $\pm \mathrm{SD}$, and independent t-test was used to investigate intergroup distinctions. $\mathrm{P}<0.05$ was considered to indicate a statistically significant difference.

\section{Results}

Target gene Notchl was successfully constructed. As shown in Fig. 1, the constructed Notch1 shRNA vector was sequenced, and the inserted sequence and locus were correct. The interfering vector plasmid of the target gene Notchl was successfully constructed.

Notch1 mRNA expression level in BCCs following Notch1 shRNA. To investigate the role of Notch1 in the BCCs, plasmid transfection was used to suppress Notchl expression in the T24 and 5637 cell lines. Notch1 expression was detected

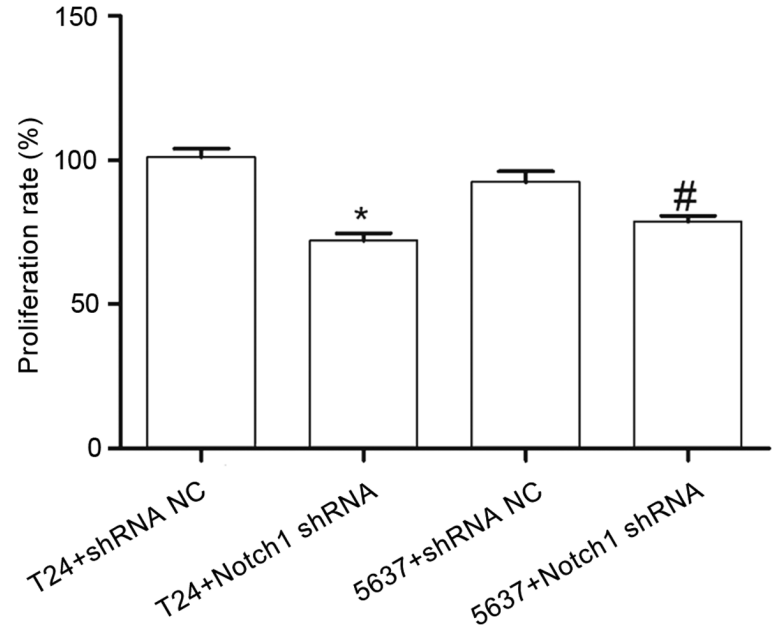

Figure 3. Changes in cell proliferation rate in the T24 and 5637 bladder cancer cells following transfection with Notch1 shRNA were detected using a MTT assay. " $\mathrm{P}<0.05$ vs. T $24+$ shRNA NC; ${ }^{\text {P }}<0.05$ vs. $5637+$ shRNA NC. shRNA, short hairpin RNA; NC, negative control.

using RT-qPCR. Compared with that in the T24+shRNA NC group, the expression level of Notch1 in the T24+Notch1 shRNA group was significantly decreased $(\mathrm{t}=16.310 ; \mathrm{P}<0.001)$. Compared with that in the $5637+$ shRNA NC group, the expression level of Notch1 in the 5637+Notch1 shRNA group was also significantly decreased $(\mathrm{t}=13.28 ; \mathrm{P}<0.001)$ (Fig. 2). These results indicated that the Notchl gene was successfully silenced and inhibited the expression of Notch1 mRNA.

Effect of Notch1 shRNA on the proliferation of the T24 and 5637 cell lines. Compared with that in the T24+shRNA NC group, the cell proliferation rate in the T24+Notch1 shRNA group was significantly decreased $(t=7.583 ; \mathrm{P}<0.05)$. Similarly, compared with that in the $5637+$ shRNA NC group, the cell proliferation rate in the $5637+$ Notch 1 shRNA group was also significantly decreased $(\mathrm{t}=3.283 ; \mathrm{P}<0.05)$ (Fig. 3$)$. These results 

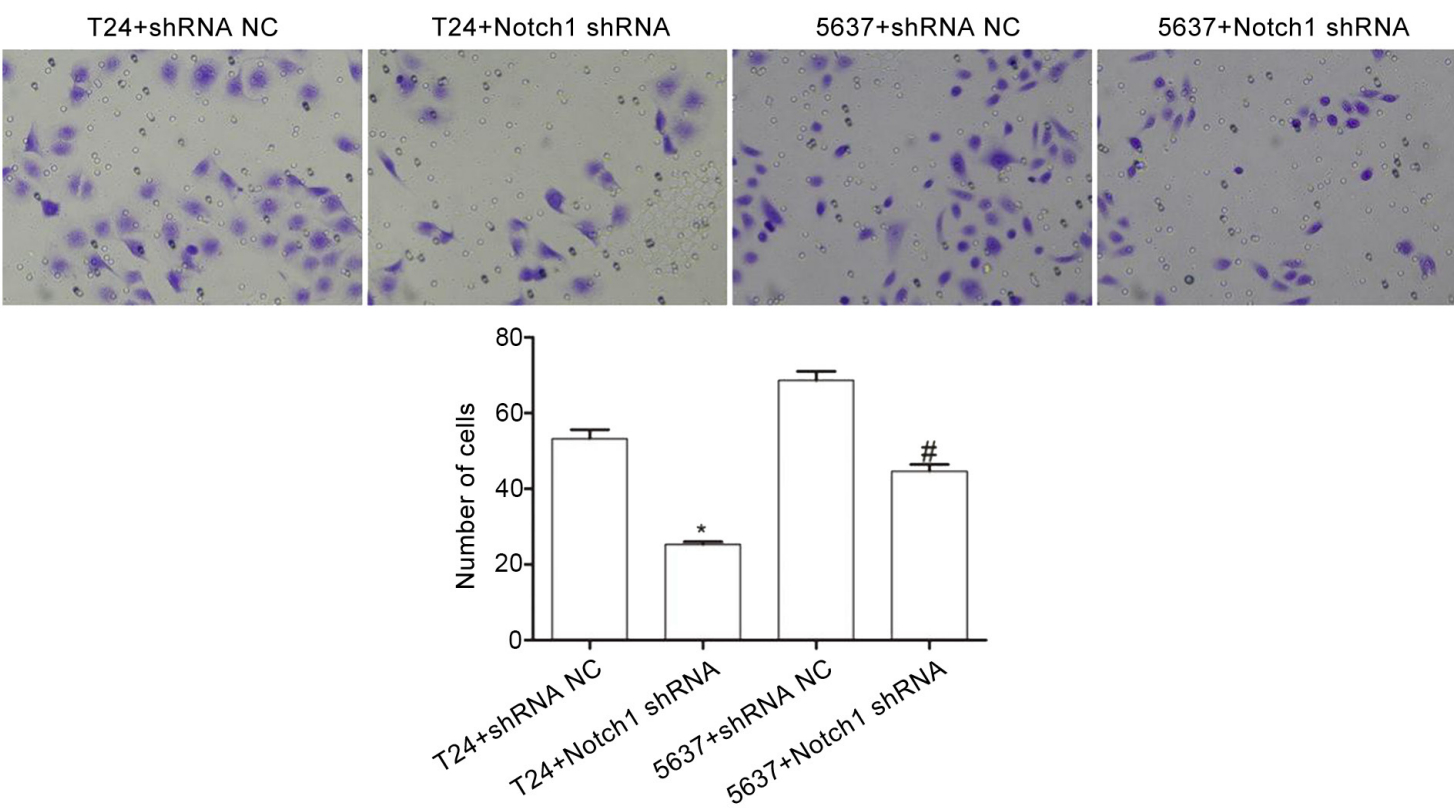

Figure 4. Changes in the number of invasive cells in the T24 and 5637 bladder cancer cell lines following transfection with Notch1 shRNA were detected using a Transwell assay. Scale, $200 \mu \mathrm{m}$. "P<0.05 vs. T24+shRNA NC; ${ }^{\# P}<0.05$ vs. 5637+shRNA NC. shRNA, short hairpin RNA; NC, negative control.

indicated that by silencing the Notchl gene, the proliferation of the T24 and 5637 cells was decreased.

Effect of Notch1 shRNA on the invasive ability of the T24 and 5637 cell lines. Compared with that in the T24+shRNA $\mathrm{NC}$ group, the number of invasive cells in the T24+Notch1 shRNA group was significantly decreased $(\mathrm{t}=11.538 ; \mathrm{P}<0.001)$. Similarly, compared with that in the $5637+$ shRNA NC group, the number of invasive cells in the 5637+Notch1 shRNA group was significantly decreased $(\mathrm{t}=8.205 ; \mathrm{P}<0.05)$ (Fig. 4). These results indicated that by silencing the Notchl gene, the invasive ability of the T24 and 5637 cells was decreased.

Effect of Notchl shRNA on apoptosis and the cell cycle in the T24 and 5637 cell lines. To investigate the effect of Notch1 on BCC apoptosis, flow cytometry was used to detect T24 and 5637 cell apoptosis upon Notch1 silencing. Compared with that in the T24+shRNA NC group, the apoptosis rate in the T24+Notch1 shRNA group was significantly increased $(\mathrm{t}=-34.083$; $\mathrm{P}<0.001)$. Compared with that in the 5637+shRNA NC group, the apoptosis rate in the 5637+Notch1 shRNA group was also significantly increased $(\mathrm{t}=-14.316$; $\mathrm{P}<0.001)$ (Fig. $5 \mathrm{~A})$. These results indicated that by silencing the Notchl gene, the rate of apoptosis of the T24 and 5637 cells was increased.

Flow cytometry was also used to investigate the cell cycle. The results revealed that compared with that in the T24+shRNA NC group, the proportion of cells in the $\mathrm{G}_{1}$ phase was significantly increased $(\mathrm{t}=-6.929 ; \mathrm{P}<0.05)$, but the proportion of cells in the $G_{2}$ phase was significantly decreased $(\mathrm{t}=5.631 ; \mathrm{P}<0.05)$ in the $\mathrm{T} 24+$ Notch1 shRNA group; no obvious differences were noted in the proportion of cells in $\mathrm{S}$ phase $(\mathrm{t}=0.264 ; \mathrm{P}=0.805)$. In addition, compared with that in the 5637+shRNA NC group, the proportion of cells in the $\mathrm{G}_{1}$ phase was significantly increased $(\mathrm{t}=-21.302 ; \mathrm{P}<0.001)$, but the proportion of cells in $\mathrm{S}$ phase was significantly decreased $(\mathrm{t}=23.462 ; \mathrm{P}<0.001)$ in the $5637+$ Notch1 shRNA group; no obvious differences were noted in the proportion of cells in the $\mathrm{G}_{2}$ phase $(\mathrm{t}=1.072 ; \mathrm{P}=0.344)$ (Fig. 5B). These results indicated that by silencing the Notch1 gene, the proportion of the T24 and 5637 cells in the $\mathrm{G}_{1}$ phase was increased.

Effect of Notch1 on the mRNA expression levels of $N$-cadherin, vimentin, Bcl2, E-cadherin, Bad and Bid in the BCCs. Compared with that in the T24+shRNA NC, the mRNA expression level of E-cadherin ( $\mathrm{t}=-8.804 ; \mathrm{P}<0.001)$, Bad $(\mathrm{t}=-11.07 ; \mathrm{P}<0.001)$, and $\mathrm{Bid}(\mathrm{t}=-10.718 ; \mathrm{P}<0.001)$ was significantly increased, but the mRNA expression level of $\mathrm{N}$-cadherin $(\mathrm{t}=11.725 ; \mathrm{P}<0.001)$, vimentin $(\mathrm{t}=12.597 ; \mathrm{P}<0.001)$, and $\mathrm{Bcl} 2(\mathrm{t}=10.627 ; \mathrm{P}<0.001)$ was significantly decreased in the T24+Notch1 shRNA group (Fig. 6).

Compared with that in the 5637+shRNA NC, the mRNA expression level of $\mathrm{E}$-cadherin ( $\mathrm{t}=-13.689$; $\mathrm{P}<0.001)$, $\mathrm{Bad}$ $(\mathrm{t}=-23.999 ; \mathrm{P}<0.001)$, and $\mathrm{Bid}(\mathrm{t}=-12.805 ; \mathrm{P}<0.001)$ was significantly increased, but the mRNA expression of $\mathrm{N}$-cadherin $(\mathrm{t}=0.105 ; \mathrm{P}<0.001)$, vimentin $(\mathrm{t}=9.649 ; \mathrm{P}<0.001)$, and $\mathrm{Bcl} 2$ $(\mathrm{t}=7.966 ; \mathrm{P}<0.001)$ was significantly decreased in the $5637+$ Notch1 shRNA group (Fig. 6). These results indicated that by silencing the Notchl gene, the mRNA expression levels of N-cadherin, vimentin and $\mathrm{Bcl} 2$ were decreased, while E-cadherin, Bad and Bid were increased in the T24 and 5637 cells.

Effect of Notchl on the protein expression levels of vimentin, $B c l 2, N$-cadherin, Bad, Bid and E-cadherin in the BCCs. The protein expression levels of apoptosis-related proteins and EMT factors in the T24 and 5637 cells were examined. Compared with that in the NC groups, the protein expression levels of E-cadherin (T24 cells, $\mathrm{t}=-6.39 ; \mathrm{P}<0.05$; and 5637 cells, $\mathrm{t}=-4.95$; $\mathrm{P}<0.05)$, Bad (T24 cells, $\mathrm{t}=-11.372 ; \mathrm{P}<0.001$; and 5637 cells, $\mathrm{t}=-6.988 ; \mathrm{P}<0.05)$, and $\mathrm{Bid}(\mathrm{T} 24$ cells, $\mathrm{t}=-13.85 ; \mathrm{P}<0.001$; and 5637 cells, $\mathrm{t}=-15.383 ; \mathrm{P}<0.001)$ were significantly increased, but the protein expression levels of $\mathrm{N}$-cadherin (T24 cells, $\mathrm{t}=9.957 ; \mathrm{P}<0.05$; and 5637 cells, $\mathrm{t}=11.624 ; \mathrm{P}<0.001$ ), vimentin 


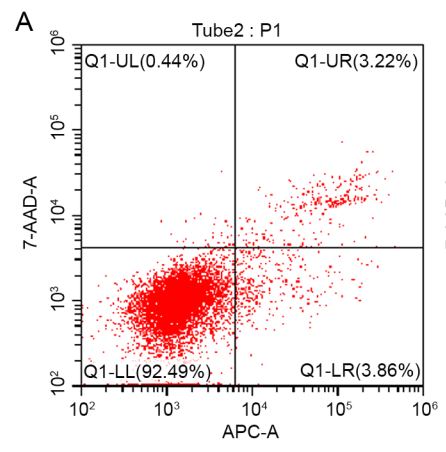

T24+shRNA NC

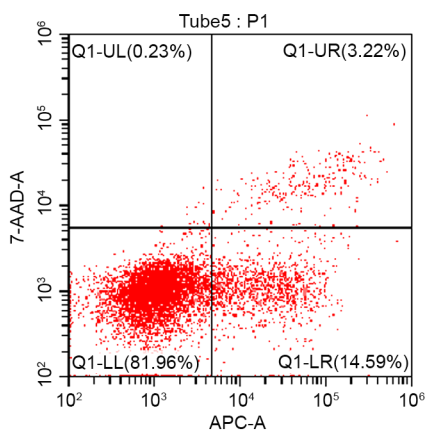

$5637+$ Notch1 shRNA

B
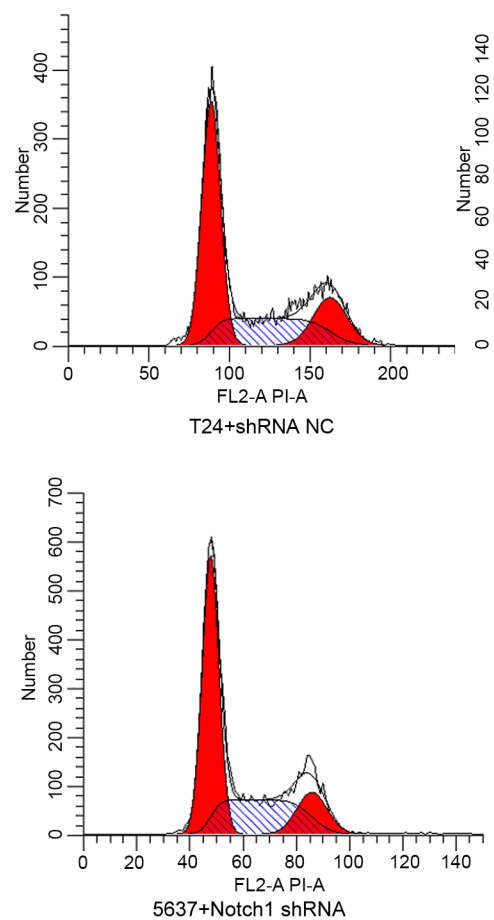

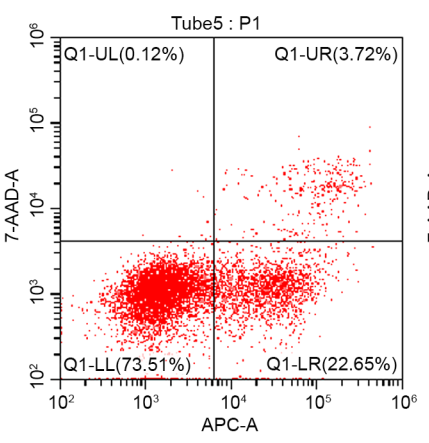

T24+Notch1 ShRNA

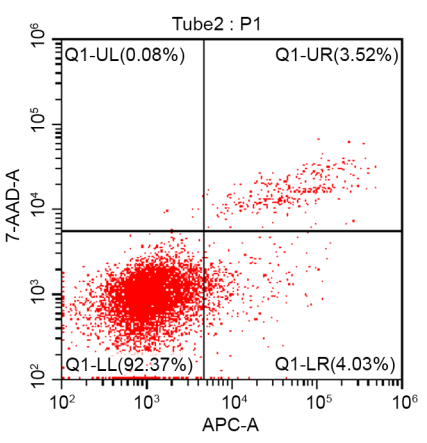

$5637+$ shRNA NC
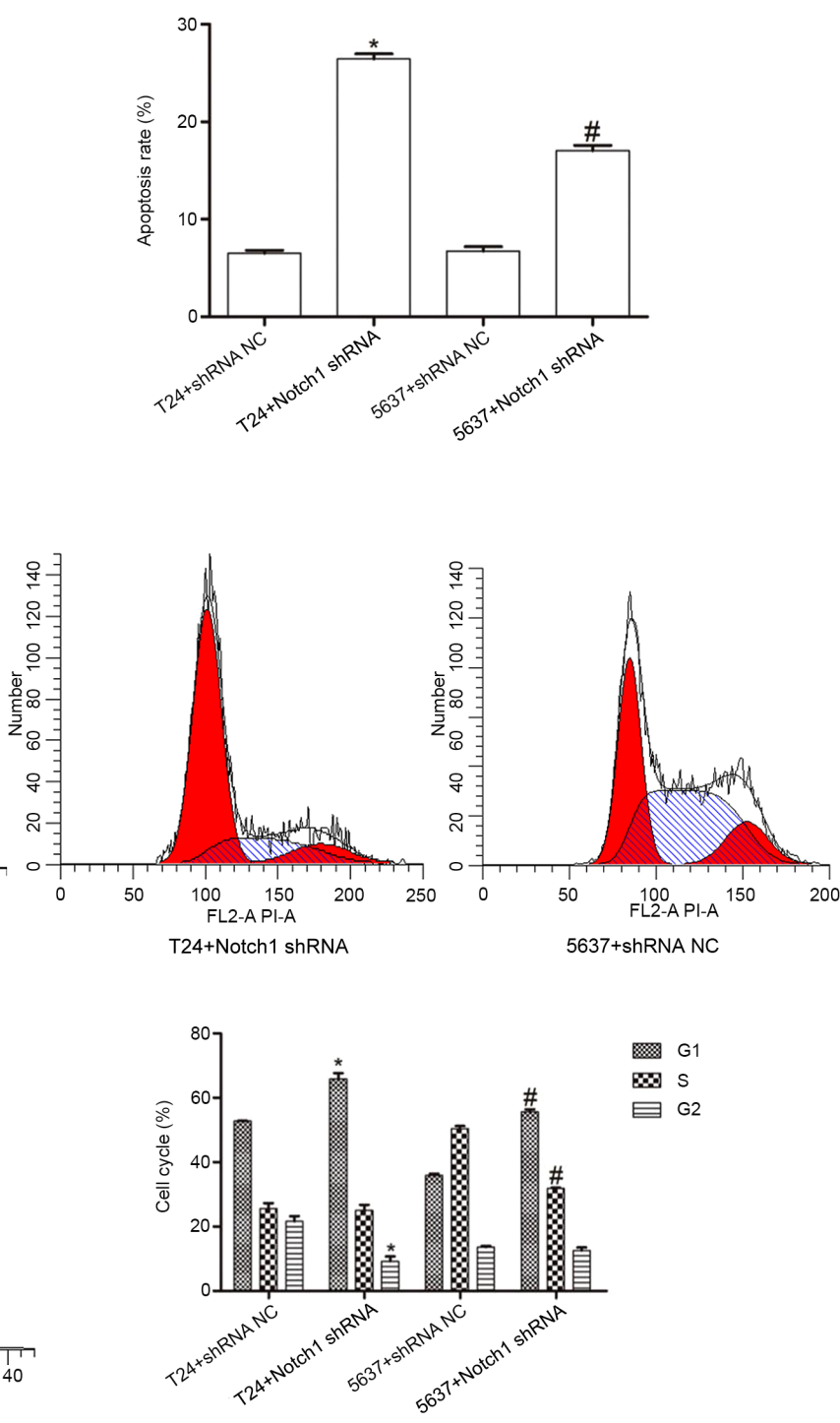

Figure 5. Changes in the apoptotic rate and cell cycle in the BCCs following transfection with Notch1 shRNA were detected using flow cytometry. (A) Apoptotic rate of the BCCs in each group. (B) Changes in the cell cycle of the BCCs cells in each group. ${ }^{*} \mathrm{P}<0.05$ vs. T24+shRNA NC; ${ }^{\#} \mathrm{P}<0.05$ vs. 5637+shRNA NC. BCCs, bladder cancer cells; shRNA, short hairpin RNA; NC, negative control.

(T24 cells, $\mathrm{t}=6.502 ; \mathrm{P}<0.05 ;$ and 5637 cells, $\mathrm{t}=4.681 ; \mathrm{P}<0.05)$, and $\mathrm{Bcl} 2$ (T24 cells, $\mathrm{t}=12.576 ; \mathrm{P}<0.001$; and 5637 cells, $\mathrm{t}=8.061 ; \mathrm{P}<0.05)$ were significantly decreased in the Notch1 shRNA group (Fig. 7). These results indicated that by silencing the Notchl gene, the protein expression levels of N-cadherin, vimentin, and $\mathrm{Bcl} 2$ were decreased, while E-cadherin, Bad and Bid were increased in the T24 and 5637 cells.

\section{Discussion}

Previous studies have confirmed that the Notch signaling pathway and EMT play key roles in the occurrence, development, and metastasis of human tumors, such as lung, breast, prostate and colorectal cancers $(14,15)$. However, in bladder cancer, the association between the Notch signaling pathway 

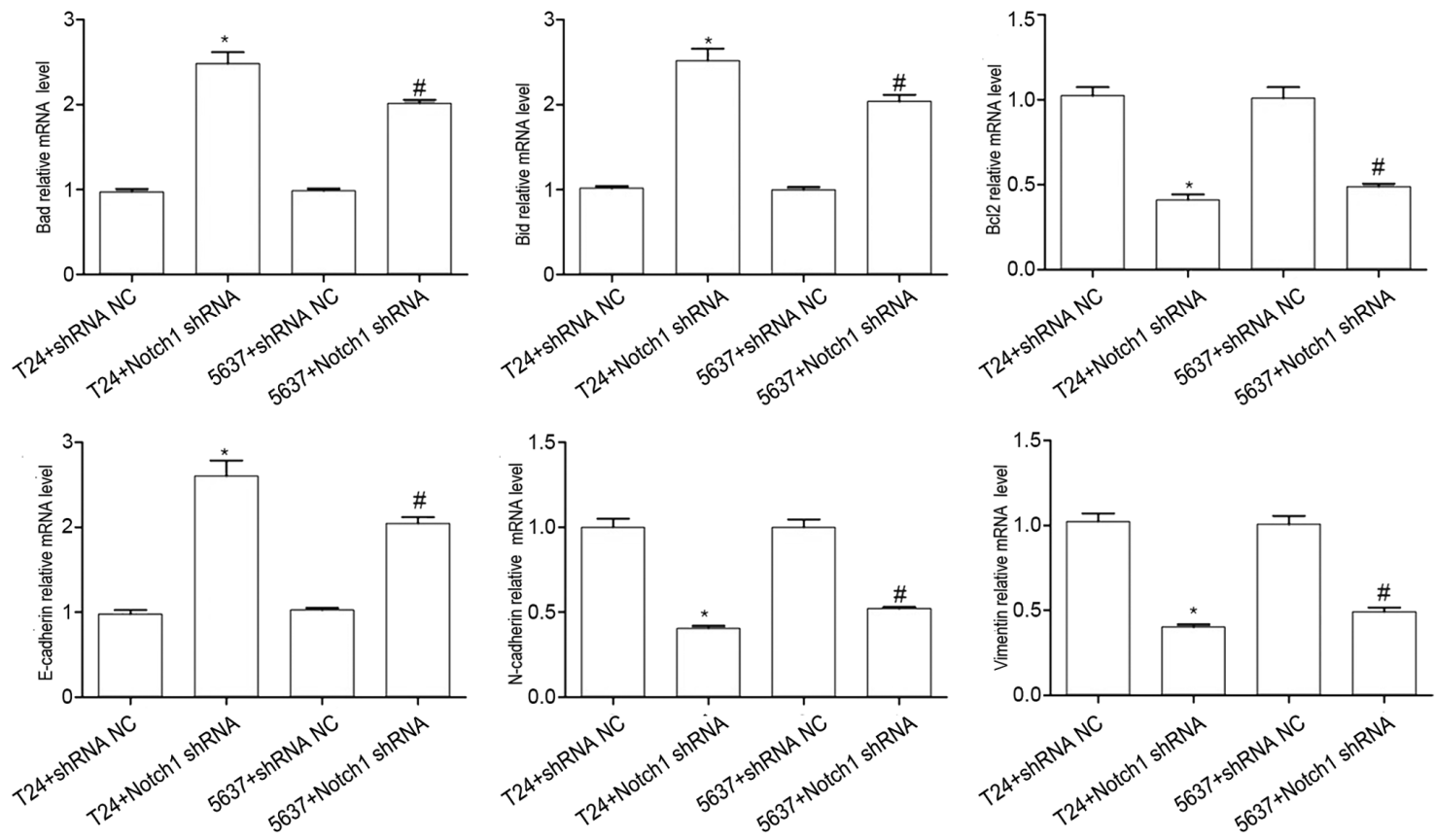

Figure 6. Changes in vimentin, Bc12, Bad, Bid, and E- and N-cadherin mRNA expression levels in the T24 and 5637 bladder cancer cells following transfection with Notch1 shRNA were detected using reverse transcription-quantiative PCR. " $\mathrm{P}<0.05$ vs. T24+shRNA NC; ${ }^{\prime} \mathrm{P}<0.05$ vs. 5637+shRNA NC. shRNA, short hairpin RNA; NC, negative control.
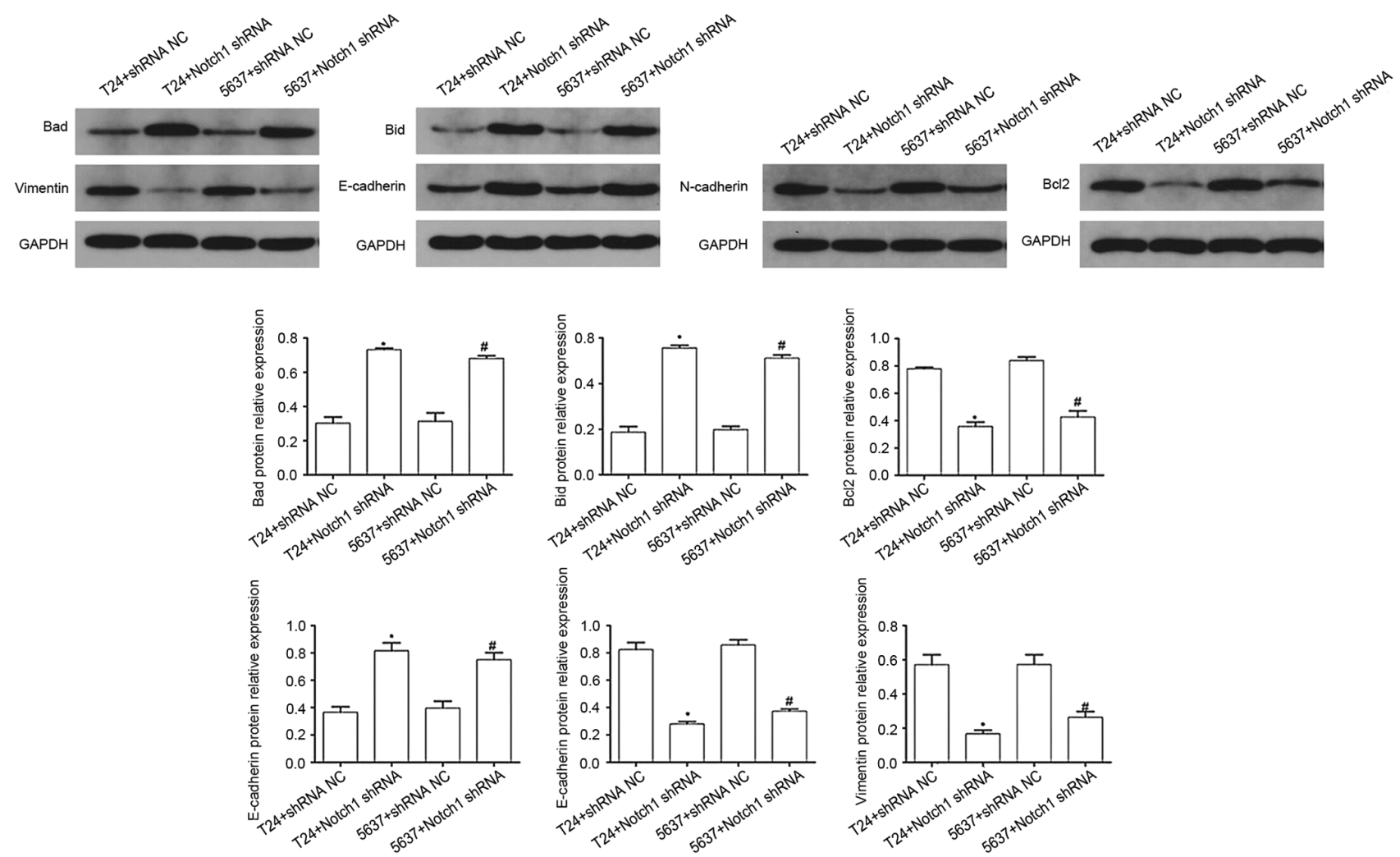

Figure 7. Changes in vimentin, Bcl2, Bad, Bid, E- and N-cadherin protein expression levels in T24 and 5637 bladder cancer cells following transfection with Notch1 shRNA were detected using western blot analysis. ${ }^{*} \mathrm{P}<0.05$ vs. T24+shRNA NC; ${ }^{\text {P }}<0.05$ vs. 5637+shRNA NC. shRNA, short hairpin RNA; NC, negative control.

and EMT has not yet been fully elucidated. The Notch signaling pathway is abundant in mammals and is involved in the regulation of numerous life processes, including the maintenance of the dynamic balance of cell differentiation, proliferation, and apoptosis $(16,17)$. The Notch signaling pathway comprises Notch receptors and ligands, as well as intracellular effector molecules (18). There are four Notch receptors, including Notch1, Notch2, Notch3 and Notch4; the Notch ligands 
include protein jagged (JAG)1, JAG2, $\delta$-like protein (DLL)1, DLL3 and DLL4 (17). An increase in the signaling levels in the Notch signaling pathway may induce the development of a variety of tumors, such as lung and breast cancers, and increase Notch1 mRNA expression level is the most frequently observed abnormality in tumor tissues, such as lung and breast (19-23). Notch1 has also been found to participate in the occurrence and development of diverse tumors, such as lung, breast, prostate and colorectal cancers by affecting cell proliferation, differentiation and apoptosis (19-23). Notchl shRNA silencing could inhibit cell proliferation and invasion of the SGC-7901 gastric cancer cell line (19). Notch1 suppression, by genetic interference, could also inhibit the proliferation and invasion of breast cancer cells (20). Goriki et al (12) reported that increased Notch1 protein expression level in bladder cancer was associated with an increased pathological grade.

In the present study, the proliferation and invasion of the BCCs upon Notch1 shRNA was significantly reduced, whereas cell apoptosis was increased. The mRNA and protein expression level of the apoptosis-related proteins, Bad and Bid in the Notch1 shRNA group was significantly increased, whereas the expression level of the anti-apoptotic protein, $\mathrm{Bcl} 2$ was significantly decreased, suggesting that inhibition of Notchl promoted apoptosis of the BCCs. These findings suggested that suppression of Notchl inhibited T24 and 5637 cell proliferation and invasion, and promoted apoptosis.

EMT refers to the ability of epithelial cells to infiltrate and migrate (by losing polarity and loosening the tight junctions between cells), which is stimulated by certain factors, such as inflammation (24). Under physiological conditions, EMT of epithelial cells can repair injured normal tissues (25). In addition, EMT assumes a critical role in tumor occurrence and progression. EMT is a starting point and an important event in metastasis cascade reactions, where epithelial cancer cells lose polarity and cell-cell contact, and therefore the migratory ability of cancer cells is enhanced (26). The E-cadherin, $\mathrm{N}$-cadherin, and vimentin proteins are related to EMT. A decrease in E-cadherin expression has been considered to be the most significant feature of EMT (27). E-cadherin maintains the tight junctions between epithelial cells and plays an important role in maintaining the morphological stability of cells (28). Increased vimentin and $\mathrm{N}$-cadherin expression ensures that cancer cells acquire mesenchymal characteristics, that promote migration and invasion (27). N-cadherin mainly mediates the adhesion between nerve tissue and fibroblasts, while vimentin is widely distributed in interstitial cells (27). Notch1 can induce EMT by mediating the expression of various EMT-related genes, such as Snail1 and Snail2 (29,30). Natsuizaka et al (31) reported that Notch1 protein expression levels were increased in NCI-H2023 squamous cell carcinoma (SCC) cell line and was associated with a poor prognosis for esophageal SCC.

To date, there have been relatively few studies on the role of the Notch1 signaling pathway in BCCs. Therefore, to investigate whether Notch1 shRNA plays a role in bladder cancer by inhibiting EMT of BCCs, the mRNA and protein expression level of EMT-related factors were detected using RT-qPCR and western blot analysis in BCCs after Notchl silencing with shRNA. E-cadherin expression level was found to be notably augmented at both the mRNA and protein expression level, whereas vimentin and $\mathrm{N}$-cadherin was reduced upon Notchl silencing. E-cadherin was associated with BCC metastasis and invasion, whereas
$\mathrm{N}$-cadherin and vimentin proteins can promote cell adhesion and signal transduction (32). This suggests that the inhibition of Notch1 may inhibit the expression level of EMT-relevant proteins, thereby inhibiting BCC invasion and metastasis.

In conclusion, inhibiting Notchl expression was found to inhibit the invasion of human BCCs, promote their apoptosis, and inhibit EMT. However, there are still a number experiments required to validate the results. Future studies should focus on the Notchl gene and its association with clinical outcomes of patients with bladder cancer.

\section{Acknowledgements}

Not applicable.

\section{Funding}

This research was supported by the Zhejiang Provincial Natural Science Foundation of China (grant no. LQ17H050002), the Natural Science Foundation of Inner Mongolia (grant no. 2017BS0805), the Doctoral Research Initiation Fund of Baotou Medical College (grant no. BSJJ201707) and the Natural Sciences-Sailing Plan of Baotou Medical College (grant no. BYJJ-YF 201616).

\section{Availability of data and materials}

The datasets used and/or analyzed during the current study are available from the corresponding author on reasonable request.

\section{Authors' contributions}

KWZ, XH, YS, QW, QM and KSZ conceived and designed the project. KWZ and $\mathrm{XH}$ acquired the data. $\mathrm{KWZ}$ and $\mathrm{XH}$ confirm the authenticity of all the raw data. KWZ, XH, YS, QW, QM and KSZ analyzed and interpreted the data. QM and KSZ wrote the manuscript. All authors read and approved the final manuscript.

\section{Ethics approval and consent to participate}

Not applicable.

\section{Patient consent for publication}

Not applicable.

\section{Competing interests}

The authors declare that they have no competing interests.

\section{References}

1. Antoni S, Ferlay J, Soerjomataram I, Znaor A, Jemal A and Bray F: Bladder cancer incidence and mortality: A global overview and recent trends. Eur Urol 71: 96-108, 2017.

2. Breyer J, Wirtz RM, Otto W, Erben P, Kriegmair MC, Stoehr R, Eckstein M, Eidt S, Denzinger S, Burger M, et al; BRIDGE Consortium: In stage pT1 non-muscle-invasive bladder cancer (NMIBC), high KRT20 and low KRT5 mRNA expression identify the luminal subtype and predict recurrence and survival. Virchows Arch 470: 267-274, 2017. 
3. Babjuk M,Böhle A, Burger M,Capoun O,Cohen D,CompératEM Hernández V, Kaasinen E, Palou J, Rouprêt M, et al: EAU guidelines on non-muscle-invasive urothelial carcinoma of the bladder: Update 2016. Eur Urol 71: 447-461, 2017.

4. Zhou Z, Zhao S, Lu Y, Wu J, Li Y, Gao Z, Yang D and Cui Y: Meta-analysis of efficacy and safety of continuous saline bladder irrigation compared with intravesical chemotherapy after transurethral resection of bladder tumors. World J Urol 37: 1075-1084, 2019.

5. Kinnaird A, Dromparis P and Evans $\mathrm{H}$ : Recurrence and upstaging rates of T1 high-grade urothelial carcinoma of the bladder on repeat resection in a Canadian, resource-limited, healthcare system. Can Urol Assoc J 12: 267-269, 2018.

6. Gordon PC, Thomas F, Noon AP, Rosario DJ and Catto JW: Long-term outcomes from re-resection for high-risk non-muscleinvasive bladder cancer: A potential to rationalize use. Eur Urol Focus 5: 650-657, 2019

7. van den Bosch S and Alfred Witjes J: Long-term cancer-specific survival in patients with high-risk, non-muscle-invasive bladder cancer and tumour progression: A systematic review. Eur Urol 60: 493-500, 2011.

8. Wu Y, Gao Q, Zhu S, Wu Q, Zhu R, Zhong H, Xing C, Qu H, Wang D, Li B, et al: Low-intensity pulsed ultrasound regulates proliferation and differentiation of neural stem cells through notch signaling pathway. Biochem Biophys Res Commun 526: 793-798, 2020

9. Qiu Z, Lin S, Hu X, Zeng J, Xiao T, Ke Z and Lv H: Involvement of miR-146a-5p/neurogenic locus notch homolog protein 1 in the proliferation and differentiation of STRO- $1^{+}$human dental pulp stem cells. Eur J Oral Sci 127: 294-303, 2019.

10. Ai X, Jia Z, Liu S, Wang J and Zhang X: Notch-1 regulates proliferation and differentiation of human bladder cancer cell lines by inhibiting expression of Krüppel-like factor 4. Oncol Rep 32: 1459-1464, 2014.

11. Maraver A, Fernandez-Marcos PJ, Cash TP, Mendez-Pertuz M, Dueñas M, Maietta P, Martinelli P, Muñoz-Martin M, Martínez-Fernández M, Cañamero M, et al: NOTCH pathway inactivation promotes bladder cancer progression. J Clin Invest 125: 824-830, 2015.

12. Goriki A, Seiler R, Wyatt AW, Contreras-Sanz A, Bhat A, Matsubara A, Hayashi T and Black PC: Unravelling disparate roles of NOTCH in bladder cancer. Nat Rev Urol 15: 345-357, 2018.

13. Livak KJ and Schmittgen TD: Analysis of relative gene expression data using real-time quantitative PCR and the 2(-Delta Delta C(T)) method. Methods 25: 402-408, 2001.

14. Li Y, Ma J, Qian X, Wu Q, Xia J, Miele L, Sarkar FH and Wang Z: Regulation of EMT by Notch signaling pathway in tumor progression. Curr Cancer Drug Targets 13: 957-962, 2013.

15. Espinoza I and Miele L: Deadly crosstalk: Notch signaling at the intersection of EMT and cancer stem cells. Cancer Lett 341: 41-45, 2013.

16. D'Angelo RC, Ouzounova M, Davis A, Choi D, Tchuenkam SM, Kim G, Luther T, Quraishi AA, Senbabaoglu Y, Conley SJ, et al: Notch reporter activity in breast cancer cell lines identifies a subset of cells with stem cell activity. Mol Cancer Ther 14: 779-787, 2015

17. Henrique D and Schweisguth F: Mechanisms of Notch signaling: A simple logic deployed in time and space. Development: Feb 1,2019 (Epub ahead of print). doi: 10.1242/dev.172148 .
18. Kovall RA, Gebelein B, Sprinzak D and Kopan R: The Canonical Notch Signaling pathway: Structural and biochemical insights into shape, sugar, and force. Dev Cell 41: 228-241, 2017.

19. Wei G, Chang Y, Zheng J, He S, Chen N, Wang X and Sun X Notch1 silencing inhibits proliferation and invasion in SGC 7901 gastric cancer cells. Mol Med Rep 9: 1153-1158, 2014.

20. Hristova NR, Tagscherer KE, Fassl A, Kopitz J and Roth W: Notch1-dependent regulation of p27 determines cell fate in colorectal cancer. Int J Oncol 43: 1967-1975, 2013.

21. Zhang Q, Yuan Y, Cui J, Xiao T and Jiang D: Paeoniflorin inhibits proliferation and invasion of breast cancer cells through suppressing Notch-1 signaling pathway. Biomed Pharmacother 78: 197-203, 2016

22. Lai XX, Li G, Lin B and Yang H: Interference of Notch 1 inhibits the proliferation and invasion of breast cancer cells: Involvement of the $\beta$ catenin signaling pathway. Mol Med Rep 17: 2472-2478, 2018.

23. Lloyd-Lewis B, Mourikis P and Fre S: Notch signalling: Sensor and instructor of the microenvironment to coordinate cell fate and organ morphogenesis. Curr Opin Cell Biol 61: 16-23, 2019.

24. Saitoh M: Involvement of partial EMT in cancer progression. J Biochem 164: 257-264, 2018.

25. Stone RC, Pastar I, Ojeh N, Chen V, Liu S, Garzon KI and Tomic-Canic M: Epithelial-mesenchymal transition in tissue repair and fibrosis. Cell Tissue Res 365: 495-506, 2016.

26. Rodriguez-Aznar E, Wiesmüller L, Sainz B Jr and Hermann PC: EMT and stemness-key players in pancreatic cancer stem cells. Cancers (Basel) 11: 1136, 2019.

27. Pastushenko I and Blanpain C: EMT Transition states during tumor progression and metastasis. Trends Cell Biol 29: 212-226, 2019.

28. Ko JH, Nam D, Um JY, Jung SH, Sethi G and Ahn KS: Bergamottin suppresses metastasis of lung cancer cells through abrogation of diverse oncogenic signaling cascades and epithelial-to-mesenchymal transition. Molecules 23: 1601, 2018.

29. van Denderen BJ and Thompson EW: Cancer: The to and fro of tumour spread. Nature 493: 487-488, 2013.

30. Matsuno Y, Coelho AL, Jarai G, Westwick J and Hogaboam CM: Notch signaling mediates TGF- $\beta 1$-induced epithelial-mesenchymal transition through the induction of Snail. Int J Biochem Cell Biol 44: 776-789, 2012

31. Natsuizaka M, Whelan KA, Kagawa S, Tanaka K, Giroux V, Chandramouleeswaran PM, Long A, Sahu V, Darling DS, Que J, et al: Interplay between Notch1 and Notch3 promotes EMT and tumor initiation in squamous cell carcinoma. Nat Commun 8 : $1758,2017$.

32. Kang J, Kim E, Kim W, Seong KM, Youn H, Kim JW, Kim J and Youn B: Rhamnetin and cirsiliol induce radiosensitization and inhibition of epithelial-mesenchymal transition (EMT) by miR-34a-mediated suppression of Notch-1 expression in non-small cell lung cancer cell lines. J Biol Chem 288: 27343-27357, 2013

This work is licensed under a Creative Commons Attribution-NonCommercial-NoDerivatives 4.0 International (CC BY-NC-ND 4.0) License. 